\title{
Scanning electron microscopic study of the in situ effect of salivary stimulation on erosion and abrasion in human and bovine enamel
}

\section{Daniela Rios $^{(a)}$ \\ Heitor Marques Honório(b) \\ Ana Carolina Magalhães ${ }^{(c)}$ \\ Salete Moura Bonifácio da Silva(d) \\ Alberto Carlos Botazzo Delbem ${ }^{(e)}$ \\ Maria Aparecida de Andrade \\ Moreira Machado(d) \\ Marília Afonso Rabelo Buzalaf(f)}

(a) Post-Doctoral Student; (f) Associate Professor - Department of Biological Sciences, School of Dentistry of Bauru, University of São Paulo.

(d) Associate Professors, Department of Pediatric Dentistry, School of Dentistry of Bauru, University of São Paulo.

(b) Assistant Professor, Department of Pediatric Dentistry, Federal University of Alfenas.

(c) Graduate Student; (e) Associate Professor - Department of Pediatric Dentistry, School of Dentistry of Araçatuba, São Paulo State University.

\section{Corresponding author:}

Marília Afonso Rabelo Buzalaf Departamento de Ciências Biológicas Faculdade de Odontologia de Bauru Universidade de São Paulo (USP)

Al. Octávio Pinheiro Brisolla, 9-75

Bauru - SP - Brazil

CEP: 17012-901

E-mail:mbuzalaf@fob.usp.br

Received for publication on Mar 29, 2007 Accepted for publication on Apr 23, 2007

\begin{abstract}
This in situ study investigated, using scanning electron microscopy, the effect of stimulated saliva on the enamel surface of bovine and human substrates submitted to erosion followed by brushing abrasion immediately or after one hour. During 2 experimental 7-day crossover phases, 9 previously selected volunteers wore intraoral palatal devices, with 12 enamel specimens ( 6 human and 6 bovine). In the first phase, the volunteers immersed the device for 5 minutes in $150 \mathrm{ml}$ of a cola drink, 4 times a day $(8 \mathrm{~h} 00,12 \mathrm{~h} 00,16 \mathrm{~h} 00$ and $20 \mathrm{~h} 00)$. Immediately after the immersions, no treatment was performed in 4 specimens (ERO), 4 other specimens were immediately brushed $(0 \mathrm{~min})$ using a fluoride dentifrice and the device was replaced into the mouth. After $60 \mathrm{~min}$, the other 4 specimens were brushed. In the second phase, the procedures were repeated but, after the immersions, the volunteers stimulated the salivary flow rate by chewing a sugar-free gum for $30 \mathrm{~min}$. Enamel superficial alterations of all specimens were then evaluated using a scanning electron microscope. Enamel prism core dissolution was seen on the surfaces submitted to erosion, while on those submitted to erosion and to abrasion (both at 0 and $60 \mathrm{~min}$ ) a more homogeneous enamel surface was observed, probably due to the removal of the altered superficial prism layer. For all the other variables - enamel substrate and salivary stimulation -, the microscopic pattern of the enamel specimens was similar.
\end{abstract}

Descriptors: Tooth abrasion; Tooth erosion; Dental enamel; Scanning electron microscopy. 


\section{Introduction}

The incidence of dental caries has declined in developed countries ${ }^{1}$ followed by the increase of other dental lesions, such as pathological tooth wear. ${ }^{2}$ In clinical situations, tooth wear can involve attrition, abrasion and erosion simultaneously. Evidence of erosion being a major factor in tooth wear has been well documented. ${ }^{3,4}$

Erosion is defined as the loss of dental hard tissue resulting primarily from non-bacterial chemical attack, usually involving acidic substances (foods and soft drinks). ${ }^{5-7}$ An acidic attack leads to demineralization and softening of the tooth surface, and to a decrease in the wear-resistance of the tooth surface, thus rendering it more susceptible to the effects of mechanical abrasion, such as those offered by tooth-brushing. ${ }^{8-10}$ Because these erosive and abrasive processes are usually observed in the mouth, efforts have been made to elucidate how erosive/abrasive lesions can be prevented.

Saliva seems to play an important role in minimizing tooth wear in erosive/abrasive attack. ${ }^{11} \mathrm{Sa}$ liva's buffering capacity, calcium and phosphate supersaturating and acquired pellicle may counteract the erosive attacks by reducing tooth demineralization, enhancing its remineralization and minimizing the surface wear by subsequent tooth-brushing procedures. ${ }^{8,12-14}$ However, Attin et al. ${ }^{8}$ (2001), in a previous study, showed that even after a 1-hour period, abrasion of the previously eroded samples was significantly higher as compared to uneroded controls or eroded unbrushed samples. There is an evident relationship between a reduced salivary flow rate and the ability to clear dietary acids from the mouth. In addition, the bicarbonate level in saliva is positively correlated with the salivary flow rate, which means that saliva produced at a high flow rate has a higher $\mathrm{pH}$ and a higher buffering capacity. ${ }^{3}$ Therefore, it may be speculated that the protective effect of saliva on eroded/abraded enamel could be enhanced by stimulating salivary flow by chewing gum.

Nevertheless, salivary parameters are not replicated in in vitro studies. This in situ study was therefore designed to evaluate by scanning electron microscopy whether a salivary flow rate stimulated by chewing gum could influence the pattern of dem- ineralization of superficial enamel submitted to erosion followed by tooth-brushing abrasion immediately or one hour after soft drink consumption. In addition, the behaviour of bovine and human dental enamel substrates in in situ erosive/abrasive lesions was compared qualitatively.

\section{Material and Methods Experimental design}

This study was approved by the Research and Ethics Committee, School of Dentistry of Bauru, University of São Paulo. The study had a crossover design, performed in two in situ phases of 7 days. The factors under study were dental substrate in two levels: human and bovine; salivary stimulation in two levels: stimulated by chewing gum and not stimulated; and time elapsed between erosive and abrasive procedures in three levels: 0 min, 1 hour and erosive challenge only. Nine volunteers wore acrylic palatal appliances, each containing twelve dental enamel slabs (6 human and 6 bovine). A new appliance was constructed for the volunteers in each phase. The groups under study in phase 1 (A, B, C), without salivary stimulation (no chewing gum) and in phase 2 (D, E, F), with salivary stimulation by chewing gum after the erosive challenge, were: groups $\mathrm{A} / \mathrm{D}$, erosive challenge only; groups $\mathrm{B} / \mathrm{E}$, abrasive procedures 0 min after erosive challenge; and groups $\mathrm{C} / \mathrm{F}$, abrasive procedures 1 hour after erosive challenge.

\section{Preparation of the enamel specimens}

Enamel slabs (4 $\times 4 \mathrm{~mm}$ ) (Figure 1.2) were obtained from recently extracted, caries-free, unerupted human third permanent molars and bovine incisor teeth (Figure 1.1), which were stored and sterilized in a $2 \%$ formaldehyde solution, $\mathrm{pH} 7.0$, for 30 days at room temperature. The enamel surface of the slabs was ground flat with water-cooled carborundum discs $(320,600$ and 1,200 grades of $\mathrm{Al}_{2} \mathrm{O}_{3}$ papers; Buehler, Lake Bluff, IL, USA), and polished with diamond spray (1 $\mu \mathrm{m}$; Buehler). A surface Knoop microhardness test was performed (five indentations in different regions of the slab, $25 \mathrm{~g}$, 5 s, HMV-2000; Shimadzu Corporation, Tokyo, Japan) to select 120 human (KHN 320-358) and 120 bovine (KHN 321-344) enamel slabs (Figure 1.3). 


\section{Palatal device preparation}

Palatal devices were made with six sites $(6 \times 6 \times 3 \mathrm{~mm})$ recessed into the polished surface of each appliance. Enamel slabs (one human and one bovine) were randomly assigned to each of the six sites and fixed with wax (Figure 1.4). In order to maintain reference surfaces, two layers of nail varnish were applied on half of the slabs surfaces.

\section{Intraoral phase}

Nine adult volunteers (four male and five female) with an average age of 25.8 years (range 2229 years) took part in this study (Figure 1.5). During the experiment the volunteers brushed their teeth with a fluoride dentifrice $(1,100 \mathrm{ppm} \mathrm{F}$ as $\mathrm{NaF}$, pH 6.8; Crest, Greensboro, NC, USA). The palatal device was worn for two phases of seven

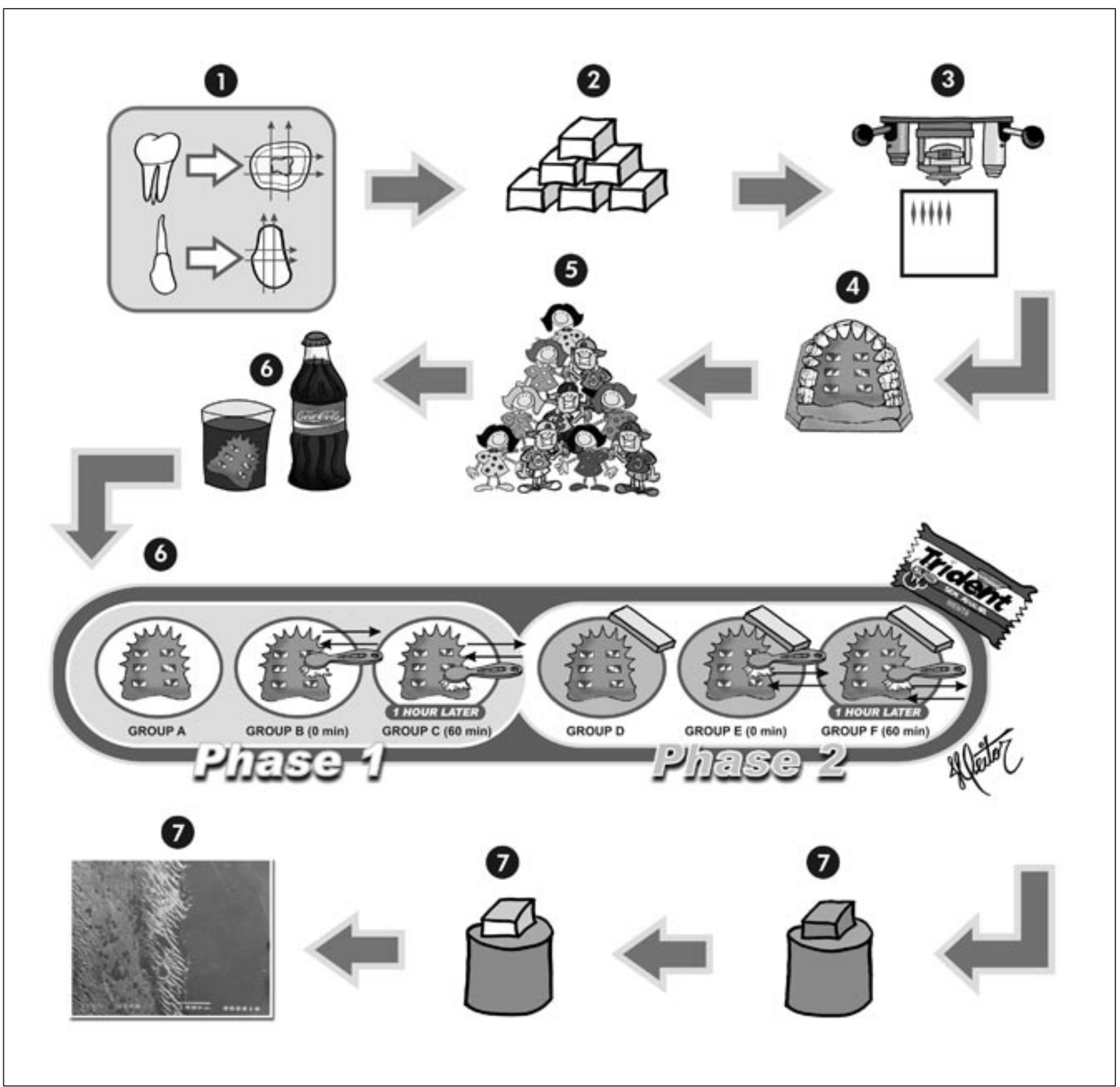

Figure 1 - (1) Human and bovine tooth sections, (2) human and bovine enamel blocks, (3) Knoop microhardness to select the blocks, (4) Two slabs were randomly assigned to each site of the device, (5) Volunteer selection, (6) Intraoral phase, (7) Scanning Electron Microscopy. 
consecutive days with an interval of 2 days between them. In the first $12 \mathrm{~h}$ of the intraoral phase, the specimens were not subjected to erosive/abrasive processes, to allow the formation of a salivary pellicle. ${ }^{13}$ During the following 7 days, erosive/ abrasive challenges were offered extraorally four times a day $(8 \mathrm{~h} 00,12 \mathrm{~h} 00,16 \mathrm{~h} 00$ and 20h00) (Figure 1.6).

In each challenge, the device was immersed in a cup containing $150 \mathrm{ml}$ of a freshly opened bottle of a cola soft drink (Coke; Companhia Fluminense de Refrigerantes, Porto Real, RJ, Brazil) for 5 minutes (Figure 1.6). Subsequently, the device was removed and specimens of groups B and E were immediately brushed by the volunteers. The brushing procedure consisted of 30 brushing strokes, made by each volunteer with a soft end-rounded toothbrush (Bitufo; Sanifil, Jundiaí, SP, Brazil) with a small portion of the described dentifrice (approximately $0.3 \mathrm{~g}$ ). Volunteers were trained and instructed to carefully perform this procedure, avoiding contact of the toothbrush and dentifrice with the remaining slabs. Groups A and D were submitted only to the erosive process. The brushed slabs were washed under running tap water and the volunteers were instructed to take one sip of the beverage, before reinserting the device into the mouth. After these procedures, in phase 1, the palatal device was kept under an unstimulated salivary flow rate; in phase 2 , it was kept under a stimulated salivary flow rate. For this purpose the volunteers chewed a tablet of sugar-free chewing gum (Trident, Cadbury Adams Indústria e Comércio, Bauru, SP, Brazil) for $30 \mathrm{~min}$. After the intraoral device had been worn for $1 \mathrm{~h}$ under different salivary conditions, in phases 1 and 2, respectively, groups $\mathrm{C}$ and $\mathrm{F}$ were brushed as described above.

The volunteers were instructed to avoid acidic foods and to wear the intraoral devices throughout the intraoral phase of the study. The devices should be removed only for the above-described procedures, during meals and for oral hygiene purposes. Plaque control on the specimens was achieved by dipping the intraoral device in a $0.2 \%$ chlorhexidine gluconate mouthrinse for $5 \mathrm{~min}$ at the end of each day of the study. ${ }^{15}$

\section{Scanning Electron Microscopy (SEM)}

The nail varnish covering half of each slab was removed with a cotton swab moistened in acetone, trying to avoid contamination of the experimental surfaces. The specimens were mounted and sputter-coated with palladium-gold in a Hammer VI cathodic evaporator (Anatech LTD, Alexandria, VA, USA). They were then examined and photographed in a JEOL JSM T220A scanning electron microscope operating at $15 \mathrm{kV}$ (Figure 1.7).

\section{Results}

SEM images allowed visualization of a distinct demarcation line at the test-control margin in all groups, as seen in Figure 2.A. Specimen surfaces that had been coated with nail varnish did not show alterations (Figure 2.A).

For the uncoated surfaces submitted to erosion only, enamel prism core dissolution was seen (Figures 2.B and 2.C), while for those submitted to erosion subjected to abrasion (both at 0 and $60 \mathrm{~min}$ ) a more homogeneous enamel surface was observed (Figures 2.D, 2.E and 2.F), probably due to the removal of the superficial altered prism layer. For the other variables, enamel substrate (Figures 2.B and 2.C) and salivary stimulation (Figures 2.E and 2.F), the pattern observed in the specimens was similar.

\section{Discussion}

The action of an acidic beverage causes dental structure loss associated to enamel demineralization. ${ }^{5,8,11,14,16}$ The findings of the present study are consistent with those available in the literature. ${ }^{17,18}$ It was observed that the action of an acidic beverage on dental structure caused demineralization of tooth surface (erosion) (Figures 2.B and 2.C) with enamel prism core dissolution.

Flattening and polishing of the specimens in this study possibly made the enamel surface more susceptible to acid dissolution than it would be under clinical conditions. ${ }^{18}$ Thus, in clinical situations the wear of enamel could be smaller, but the pattern of demineralization should be similar. Meurman, Frank $^{18}$ (1991) also observed enamel prism core dissolution in the non-polished area submitted to erosion. On the other hand, Eisenburger et al..$^{17}$ (2004) 

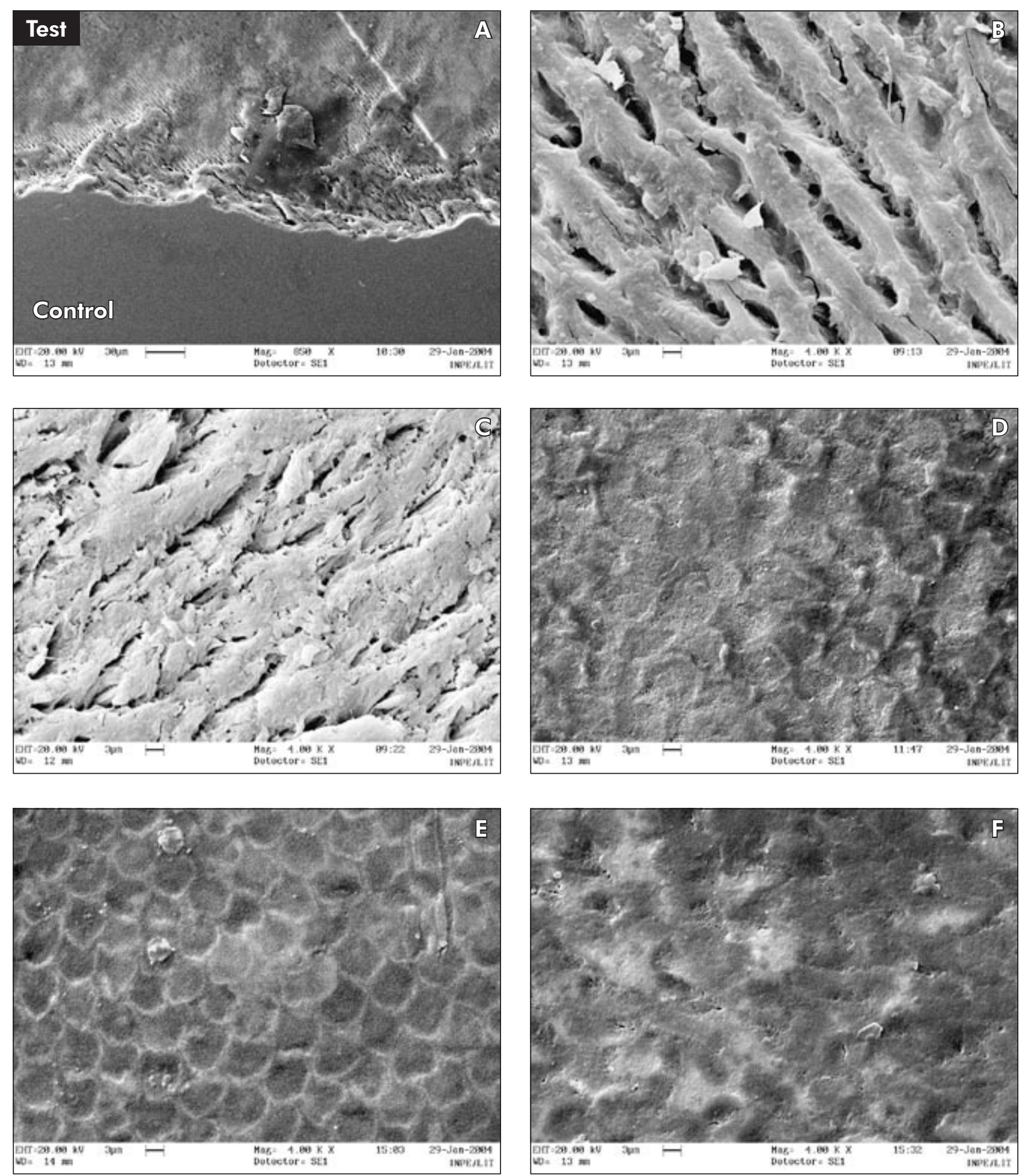

Figure 2 - (A) Bovine enamel: phase 1, abrasive procedures 0 min after erosion. Test-control margin (X 850). (B) Bovine enamel: phase 1, erosive challenge only (X 4,000). (C) Human enamel: phase 1, erosive challenge only (X 4,000). (D) Human enamel: phase 1, abrasive procedures 0 min after erosion (X 4,000). (E) Human enamel: phase 2, abrasive procedures 1 hour after erosion (X 4,000). (F) Human enamel: phase 1, abrasive procedures 1 hour after erosion $(X 4,000)$. 
in an in vitro study reported that the outer region of softened enamel is much more delicate than previously thought because the conventional preparation methods, as used in the present study, tend to introduce artifact on the SEM images. The authors suggest that the acid of the erosive attack must be titrated to $\mathrm{pH} 7$ before rinsing the slabs to be examined by scanning electron microscopy to prevent mineral precipitation. However, in the present in situ study, a remineralization period of $16 \mathrm{~h}$ was allowed after the last acid challenge. Thus, remineralization had already occurred in the oral environment, resulting in an image that simulates the clinical situation.

The demineralization of the outer surface by the acid beverage makes tooth surface more susceptible to wear derived from mechanical forces. ${ }^{8,9,14}$ Usually after consumption of beverages and foods, people brush their teeth to prevent caries development, thus exerting mechanical efforts on the enamel surface. ${ }^{19,20}$ Acidic components of foods may lead to erosion, thus potentializing wear by tooth-brushing. ${ }^{8,9,14}$ Although several studies have investigated dental erosion and its association to tooth-brushing at different intervals, ${ }^{8,13,14,16}$ this is the first report comparing erosion and erosion submitted to abrasion using scanning electron microscopy as the outcome variable.

When the enamel surface, weakened by the action of the acidic beverage, was subjected to brushing, there was loss of softened tooth enamel, thus exposing a less altered surface (Figures 2.D, 2.E and 2.F). Several authors have postulated that toothbrushing after an erosive attack should be delayed to allow the saliva to exert its natural remineralizing action on the eroded enamel, thereby resulting in increased resistance to abrasion. ${ }^{8,14,16}$ In this study the brushing delay ( $1 \mathrm{~h}$ - Figure 2.E) did not show qualitative differences on the microscopic images of enamel surfaces, in comparison to immediate toothbrushing ( $0 \mathrm{~min}$ - Figure 2.D). These results suggest that regardless of the demineralization degree, a layer of enamel was removed in both situations, thus resulting in similar images. This, however, does not exclude the possible existence of quantitative differences, as observed in previous studies. ${ }^{8,14,16}$

In view of the importance of the salivary parameters in decreasing the risk for erosion development, ${ }^{3,6}$ the in situ experimental model allowed to assess the effect of a stimulated salivary flow rate in the protective action against erosion, as observed for dental caries. ${ }^{21,22}$ The erosive process seems to be not totally irreversible. In adittion, the resting saliva is not able to yield complete remineralization of the eroded enamel. ${ }^{23}$ It is important to point out that the microscopic images of this study showed that the stimulation of saliva (phase 2 - Figure 2 . E) resulted in a similar pattern of superficial mineralization when compared to that of residual saliva (phase 1 - Figure 2.F). The sugar-free chewing gum was unable to promote complete enamel recovery.

The results of this study did not show differences between human and bovine enamel (Figures 2.B and 2.C). However, bovine enamel has been shown to be about three times more liable to dissolution in a gelatin lactic acid system than human enamel. ${ }^{24}$

Nevertheless, it is important to emphasize that the results of this qualitative in situ study provide only indications of what actually happens in the oral cavity. Further quantitative studies should be conducted to confirm the validity of these observations.

\section{Conclusions}

The findings of this study demonstrated that a stimulated salivary flow did not result in a different pattern of demineralization. The brushing abrasion of eroded enamel, regardless of being performed immediately or after one hour, resulted in less altered enamel. Both human and bovine substrates were proved adequate for erosion/abrasion investigations.

\section{Acknowledgements}

The authors would like to gratefully acknowledge all the volunteers who participated in this study and the Instituto Nacional de Pesquisas Espaciais (INPE) for utilization of the scanning electron microscope. This study was supported by CAPES. 


\section{References}

1. Peterson G, Bratthall D. The caries decline: a review of reviews. Eur J Oral Sci. 1996;104(4):436-43.

2. Attin T, Zirkel C, Hellwig E. Brushing abrasion of eroded dentin after application of sodium fluoride solutions. Caries Res. 1998;32(5):344-50.

3. Moss SJ. Dental erosion. Int Dent J. 1998;48(6):529-39.

4. Smith BG, Knight JK. An index for measuring the wear of teeth. Br Dent J. 1984;156(12):435-8.

5. Imfeld T. Dental erosion. Definition, classification and links. Eur J Oral Sci. 1996;104(2):151-5.

6. Lussi A, Jaeggi T, Zero D. The role of diet in the aetiology of dental erosion. Caries Res. 2004;38(Suppl 1):34-44.

7. Ten Cate JM, Imfeld T. Dental erosion, summary. Eur J Oral Sci. 1996;104(4):241-4.

8. Attin T, Knofel S, Buchalla W, Tutuncu R. In situ evaluation of different remineralization periods to decrease brushing abrasion of demineralized enamel. Caries Res. 2001;35(2): 216-22.

9. Davis WB, Winter PJ. The effect of abrasion on enamel and dentine and exposure to dietary acid. Br Dent J. 1980;148(1112):253-6.

10. Lussi A, Jaeggi T, Megert B. Effect of amine/sodium fluoride rinsing on toothbrush abrasion of softened enamel in situ. Caries Res. 2004;38(6):567-71.

11. Amaechi BT, Higham SM. Eroded enamel lesion remineralization by saliva as a possible factor in the site-specificity of human dental erosion. Arch Oral Biol. 2001;46(8):697-703.

12. Hall AF, Buchanan CA, Millett DT, Creanor SL, Strang R, Foye RH. The effect of saliva on enamel and dentine erosion. J Dent. 1999;27(5):333-9.

13. Hara AT, Turssi CP, Teixeira EC, Serra MC, Cury JA. Abrasive wear on eroded root dentine after different periods of exposure to saliva in situ. Eur J Oral Sci. 2003;111(5):423-7.
14. Jaeggi T, Lussi A. Toothbrush abrasion of erosively altered enamel after intraoral exposure to saliva: an in situ study. Caries Res. 1999;33(6):455-61.

15. West NX, Hughes JA, Parker DM, Newcombe RG, Addy M. Development and evaluation of a low erosive blackcurrant juice drink. 2. Comparison with a conventional blackcurrant juice drink and orange juice. J Dent. 1999;27(5):341-4.

16. Attin T, Buchalla W, Gollner M, Hellwig E. Use of variable remineralization periods to improve the abrasion resistance of previously eroded enamel. Caries Res. 2000;34(1):48-52.

17. Eisenburger M, Shellis RP, Addy M. Scanning electron microscopy of softened enamel. Caries Res. 2004;38(1):67-74.

18. Meurman JH, Frank RM. Scanning electron microscopic study of the effect of salivary pellicle on enamel surface. Caries Res. 1991;25(1):1-6.

19. Addy M, Hunter ML. Can tooth brushing damage your health? Effects on oral and dental tissues. Int Dent J. 2003;53(Suppl 3):177-86.

20. Al-Dlaigan YH, Shaw L, Smith AJ. Dental erosion in a group of British 14-year-old, school children. Part III: Influence of oral hygiene practices. Br Dent J. 2002;192(9):526-30.

21. Imfeld T, Birkhed D, Lingstrom P. Effect of urea in sugar-free chewing gums on $\mathrm{pH}$ recovery in human dental plaque evaluated with three different methods. Caries Res. 1995;29(3):172-80.

22. Machiulskiene V, Nyvad B, Baelum V. Caries preventive effect of sugar-substituted chewing gum. Community Dent Oral Epidemiol. 2001;29(4):278-88.

23. Gedalia I, Dakuar A, Shapira L, Lewinstein I, Goultschin J, Rahamim E. Enamel softening with Coca-Cola and rehardening with milk or saliva. Am J Dent. 1991;4(3):120-2.

24. Featherstone JD, Mellberg JR. Relative rates of progress of artificial carious lesions in bovine, ovine and human enamel. Caries Res. 1981;15(1):109-14. 